\title{
INEQUALITIES RELATED TO HEINZ AND HERON MEANS
}

\section{LIMIN ZOU}

Abstract. We present a matrix inequality related to Heinz and Heron means, and show that it is a refinement of some improved Heinz inequalities for matrices.

Mathematics subject classification (2010): 15A15, 15A42, 15A60.

Keywords and phrases: Heinz means, Heron means, Heinz inequality, unitarily invariant norms.

\section{REFERENCES}

[1] R. BHATIA, Interpolating the arithmetic-geometric mean inequality and its operator version, Linear Algebra Appl. 413 (2006), 355-363.

[2] R. BhatiA, C. DAVIS, More matrix forms of the arithmetic-geometric mean inequality, SIAM J. Matrix Anal. Appl. 14 (1993), 132-136.

[3] D. DRISSI, Sharp inequalities for some operator means, SIAM J. Matrix Anal. Appl. 28 (2006), 822828.

[4] C. He, L. Zou, S. QAISAR, On improved arithmetic-geometric mean and Heinz inequalities for matrices, J. Math. Inequal. 6 (2012), 453-459.

[5] X. HU, Some inequalities for unitarily invariant norms, J. Math. Inequal. 6 (2012), 615-623.

[6] F. Kittaneh, On the convexity of the Heinz means, Integr. Equ. Oper. Theory. 68 (2010), 519-527.

[7] F. Kittaneh, Y. Manasrah, Improved Young and Heinz inequalities for matrices, J. Math. Anal. Appl. 361 (2010), 262-269.

[8] S. WANG, L. ZOU, Y. JIANG, Some inequalities for unitarily invariant norms of matrices, J. Inequal. Appl. 2011 (2011), 10.

[9] X. Zhan, Inequalities for unitarily invariant norms, SIAM J. Matrix Anal. Appl. 20 (1998), 466-470.

[10] L. Zou, On some matrix inequalities, Acta. Math. Sin, Chinese Ser. 55 (2012), 715-720. 